\title{
Ambiente turístico empreendedor: um estudo com empreendedores de Paranaguá - Paraná - Brasil
}

\section{Touristic entrepreneurial environment: a study with entrepreneurs of Paranaguá - Paraná - Brazil}

\author{
Raquel dos Santos Vieira (VIEIRA, R. dos S.) ${ }^{*}$ e Miguel Bahl (BAHL, M.) **
}

RESUMO - Parte do desenvolvimento local de um município depende de ações empreendedoras ligadas ao setor de turismo. Para que iniciativas empreendedoras ocorram, é necessário que o ambiente onde estejam inseridas seja propício a empreender. Assim ocorrendo, o presente trabalho ${ }^{1}$ foi elaborado pela importância de entender o conceito de ambiente empreendedor no turismo e da valorização dos sujeitos empreendedores e objetivou identificar quais seriam as características que tornam um ambiente propício ao empreendedorismo no turismo a partir de um estudo com empreendedores participantes do curso de capacitação em Gestão Empresarial do Programa Bom Negócio Paraná no município de Paranaguá (Paraná, Brasil). Os resultados da coleta de dados, realizada em abril de 2015, com um total de 12 participantes apontaram que um ambiente é propício a empreender quando há apoio dos familiares e incentivos do setor público.

Palavras-chave: Empreendedorismo; Ambiente Turístico Empreendedor; Paranaguá (Paraná, Brasil).

ABSTRACT - Piece of local development of a municipality depends of entrepreneurial actions related to tourism trade. To entrepreneurial initiatives occur it is necessary that the environment where inserted be conducive to enterprises creation. This study was elaborated by importance to understand the definition of entrepreneurial environment on tourism and the entrepreneur's valorization. The objective was identify what are the characteristics that make an environment favorable to entrepreneurship on tourism with a study with participating entrepreneurs of the business management course of the

\footnotetext{
Formação: Graduação em Gestão e Empreendedorismo (Bacharelado), Mestrado em Turismo e Estudante do Programa de Pós-Graduação de Doutorado em Meio Ambiente e Desenvolvimento, todos sediados na Universidade Federal do Paraná (UFPR). Atividade profissional: Atua como bolsista recémformada de nível superior no Programa Bom Negócio Paraná - Programa do Governo do Estado do Paraná em parceria com a Universidade Estadual do Paraná - UNESPAR campus de Paranaguá, onde leciona aulas de gestão empresarial e realiza consultorias empresariais para empreendedores da Região Metropolitana de Curitiba e Litoral do Paraná. E-mail: raquelsantosufpr@gmail.com

** Formação: Graduação em Turismo e Licenciaturas em Geografia e em Estudos Sociais pela Universidade Federal do Paraná (UFPR). Mestrado e Doutorado em Turismo em Ciências da Comunicação pela Universidade de São Paulo (USP). Estágio pós-doutoral desenvolvido na Universidade de Girona (Espanha). Atividade profissional: Professor do Departamento de Turismo da UFPR junto ao curso de Graduação em Turismo e aos Programas de Mestrado em Turismo e Mestrado e Doutorado em Geografia. Editor da Revista Turismo e Sociedade. E-mail: migbahl@ufpr.br

1 Artigo apresentado preliminarmente no formato de trabalho junto ao IX Fórum Internacional de Turismo do Iguassu, evento paralelo ao Festival de Turismo das Cataratas do Iguaçu, que ocorreu entre os dias 17 e 19 de junho de 2015 na cidade de Foz do Iguaçu (Paraná, Brasil), selecionado entre os melhores trabalhos.
} 
Programa Bom Negócio Paraná in Paranaguá - Paraná - Brazil. The results of data collection that held in April 2015, with 12 participants indicated that a environment is favorable to entrepreneur when there is a parents support and public sector incentives.

Key words: Entrepreneurship; Touristic entrepreneurial environment; Paranaguá (Paraná, Brazil). 


\section{INTRODUÇÃO}

O turismo pode ser um setor chave para o Brasil, pois uma gestão adequada de tal setor pode impulsionar o desenvolvimento de setores diretamente a ele ligados (TOMAZZONI, 2007).

Nas últimas décadas, o mundo tem passado por inúmeras transformações nos setores da economia e o setor de turismo segue a mesma regra. Considerando a relação do turismo com o desenvolvimento local, é válido observar o comportamento das pequenas empresas que constituem o setor turístico, suas atividades, sua ocupação no mercado, seus empreendedores e o ambiente onde estão inseridas. Muitas vezes são essas empresas as principais responsáveis por inovações que geram a conservação do turismo em diversas regiões. Para Dornelas (2001), se está vivendo a era do empreendedorismo. Segundo ele:

São os empreendedores que estão eliminando barreiras comerciais e culturais, encurtando distâncias, globalizando e renovando os conceitos econômicos, criando novas relações de trabalho e novos empregos, quebrando paradigmas e gerando riqueza para a sociedade. (DORNELAS, 2001, p. 21).

Muitos são os aspectos relacionados ao empreendedorismo e ao empreendedor que merecem atenção. Existem pesquisadores atuais que enfatizam as características individuais de perfil empreendedor, como Silva, Fonseca e Alberto (2015); Santos Vieira, Santos e Rojo (2013). Tais características consideradas como essenciais a um empreendedor podem levar um indivíduo a tomar iniciativa de inovar em seus empreendimentos, gerando bons frutos para seu negócio e para uma determinada localidade ou região. No entanto, autores como Dolabela $(2008,1999)$ e Dornelas (2001) chamam a atenção para suas redes de relacionamentos formais e informais, das quais podem surgir os primeiros clientes e consumidores de um produto ou serviço. Ainda deve ser levado em consideração o ambiente em que o empreendedor está inserido. Para Dolabela (2008, p. 23), empreender:

Não é um fenômeno individual, não é um dom que poucos têm. É coletivo, comunitário. A comunidade tem o empreendedor que merece, porque cabe a ela criar o ambiente propício. A tese de que o empreendedor é fruto de herança genética não encontra mais seguidores. $\mathrm{O}$ ambiente favorável ao desenvolvimento empreendedor (em comunidades ou empresas) pode prescindir de elevadas doses de democracia (e não de autocracia), cooperação (e não somente de competição) e relações sociais estruturadas em rede (e não hierarquizadas). 
Estudos como o relatório do Global Entrepreneurship Monitor - GEM (2013) apontam que o empreendedorismo é um fenômeno complexo e multifacetado e devido a isso, deve-se avançar nas pesquisas sobre o tema. Além de estudar características do comportamento empreendedor, deve-se ainda procurar conhecer e compreender as características do ambiente social onde o indivíduo está inserido e que conduz favoravelmente ao empreendedorismo.

Dolabela (2008) afirma ainda que o empreendedor é um ser social, produto e resultado do meio em que vive. Dessa forma, se uma pessoa vive em um ambiente em que os empreendedores são vistos como algo positivo, terá isso como motivação para empreender. Partindo dessa afirmação, objetivou-se nesse estudo, identificar quais seriam as características que tornam um ambiente propício ao empreendedorismo no turismo.

Para atingir o objetivo pretendido realizou-se um estudo com empreendedores participantes do curso de capacitação em Gestão Empresarial do Programa Bom Negócio Paraná no município de Paranaguá (Paraná, Brasil).

Esse estudo está dividido em quatro seções além desta introdução. Em um primeiro momento é apresentada a fundamentação teórica que serviu de embasamento para a pesquisa, abordando conceitualmente sobre empreendedor, empreendedorismo e as características apontadas por pesquisadores dessa área como propícias a um ambiente empreendedor. Na segunda seção são apresentados os materiais e métodos utilizados para a realização do estudo. Na sequência apresentam-se os resultados obtidos a partir da coleta de dados, para por fim, na quarta seção tecer as considerações finais.

\section{FUNDAMENTAÇÃO TEÓRICA}

Referente à fundamentação teórica realizada para esse artigo foi feita uma pesquisa sobre os temas: Empreendedor, Empreendedorismo e Ambiente Turístico Empreendedor com a intenção de explorar como o tema vem sendo estudado e suas diversas abordagens, como serão apresentados na sequência. 


\subsection{EMPREENDEDOR E EMPREENDEDORISMO}

Os temas empreendedor e empreendedorismo são subjetivos, o que torna suas conceituações uma tarefa um tanto quanto complexa. São livres traduções dos vocábulos entrepreneur (DORNELAS, 2001) e entrepreneurship (DOLABELA, 1999) respectivamente, de origem francesa, onde o primeiro refere-se a "aquele que assume riscos e começa algo novo" (DORNELAS, 2001, p. 27) e o segundo é utilizado para designar estudos relativos ao empreendedor, seu perfil, suas origens, seu sistema de atividades e seu universo de atuação (DOLABELA, 1999) no qual estão contidas as ideias de iniciativa e inovação (DOLABELA, 2008).

Por trás de toda e qualquer ação, está um indivíduo, ator responsável pela ação. No empreendedorismo não seria diferente. Por trás de toda e qualquer ação empreendedora, existe um empreendedor. Dessa forma, é relevante destacar a importância do empreendedor, protagonista do empreendedorismo. Para Dornelas (2001, p. 37): “o empreendedor é aquele que detecta uma oportunidade e cria um negócio para capitalizar sobre ela, assumindo riscos calculados".

De acordo com Dolabela (1999, p. 44) "não se pode dissociar o empreendedor da empresa que criou. Ambos fazem parte do mesmo conjunto e devem ser percebidos de forma holística: a empresa tem a cara do dono".

O economista austríaco Schumpeter (citado por DOLABELA, 2008) associa o empreendedorismo ao desenvolvimento econômico, à inovação e ao aproveitamento de oportunidades em negócios. Conforme Dolabela (2008), o conceito de empreendedorismo trata de comunidades, cidades, regiões, países, implica a ideia de sustentabilidade e é a melhor arma contra o desemprego. O autor afirma ainda que "o empreendedor deve ter um compromisso com a localidade em que atua. Não basta ter um bom faturamento, um bom lucro. É preciso contribuir para o bem estar social do local" (DOLABELA, 2008, p. 24).

O empreendedorismo pode ser considerado como fator determinante para o crescimento econômico, criando empregos, riqueza e prosperidade, difundindo avanços tecnológicos e inovações, gerando concorrência e ampliando o comércio (DORNELAS, 2001; GEM, 2010). Para gerar de fato o desenvolvimento local é necessário que o empreendimento se enquadre no empreendedorismo por oportunidade, onde o 
empreendedor cria uma empresa com planejamento prévio, tendo em mente o crescimento que quer alcançar para a empresa e visando a geração de lucros, empregos e riquezas. Observa-se que a maioria dos empreendimentos que se tornam bem sucedidos são aqueles constituídos a partir da identificação de uma oportunidade de mercado (DORNELAS, 2001; DOLABELA, 2008).

A decisão de empreender ocorre devido a fatores externos, ambientais e sociais, a aptidões pessoais ou a um somatório de todos esses fatores, críticos para a criação e crescimento de empresas. Dentre esses fatores, Dornelas (2001) cita fatores sociológicos, como: influência da família, amigos, pessoas de sucesso e redes de contatos e os fatores ambientais, tais como: competição do mercado, recursos existentes, incubadoras e as políticas públicas. Pimentel et al (2013) agrupa os fatores que influenciam o processo de criação de empreendimentos em micro e macro. $\mathrm{O}$ grupo micro refere-se aos fatores pessoais do empreendedor, como: energia, disposição de correr riscos, autoconfiança, educação, experiência profissional, assim com incentivo de amigos, familiares e a vivência em ambientes empreendedores. Já no grupo macro, estão contidos fatores da dimensão político/econômica e social, como: legislação, políticas públicas, concorrência e recursos governamentais.

\subsection{AMBIENTE TURÍSTICO EMPREENDEDOR}

Nas pesquisas sobre empreendedorismo se evidenciam, de maneira geral, as características e motivações do indivíduo enquanto empreendedor, sendo que poucas se preocupam com fatores externos que podem vir a favorecer ou desfavorecer a criação de novos negócios.

O ambiente empreendedor pode ser definido como o contexto onde os mecanismos envolvidos são utilizados de forma integrada. Para Bygrave e Minniti (2000, p. 26):

Empreendedorismo leva a mais empreendedorismo e o nível da atividade empreendedora é resultado de um processo dinâmico no qual o ambiente social é tão importante quanto os fatores econômicos e legais.

Como propõe Dolabela $(1999,2008)$ uma pessoa terá motivação para empreender se estiver inserida em um ambiente onde ser empreendedor seja visto de 
maneira positiva. Dessa forma, compreende-se que empreender não se trata de um fenômeno individual, mas coletivo e comunitário onde "a comunidade tem o empreendedor que merece, porque cabe a ela criar o ambiente propício" (DOLABELA, 2008, p. 23). Nesse sentido, Dolabela (2003, p. 29) afirma que "empreender significa modificar a realidade para dela obter a auto-realização e oferecer valores positivos para a coletividade".

O empreendedorismo não é apenas um fenômeno econômico, mas também social (DOLABELA, 2008), onde o empreendedor é caracterizado como "um ser social, fruto do meio em que vive" (p. 23). Conforme o autor, o empreendedorismo compreende ainda um fenômeno local em que existem cidades, regiões e países mais, ou menos, empreendedores do que outros e que "o perfil empreendedor (fatores do comportamento e atitudes que contribuem para o sucesso) pode variar de um lugar para outro" (p. 23).

De acordo com Dolabela (2003), as condições indispensáveis para a materialização do espírito empreendedor estão no macro ambiente, na democracia, na cooperação e na estrutura do poder tendendo para a formação de redes. Ao se levar em conta o turismo como uma atividade que propicia o encontro entre pessoas de diferentes cidades, regiões e países, considerou-se ser necessária tecer a observação do papel exercido por diferentes atores sociais de forma a elucidar sua importância no desenvolvimento e consolidação de um ambiente turístico favorável socialmente à criação de novos empreendimentos e à inovação.

\section{MATERIAIS E MÉTODOS}

Nessa seção serão apresentados os procedimentos metodológicos adotados para a pesquisa e sobre o Município de Paranaguá que sediou as pesquisas de campo desse estudo.

\subsection{PROCEDIMENTOS METODOLÓGICOS}

Este estudo pode ser caracterizado como qualitativo quanto à abordagem e como exploratório, quanto aos objetivos. 
Um estudo qualitativo, de acordo com Creswell (2010), é estruturado em termos de palavras, onde se utiliza da pesquisa qualitativa como "um meio para explorar e para entender o significado que os indivíduos ou os grupos atribuem a um problema social ou humano" (p. 26). A pesquisa qualitativa foi escolhida pela intenção de coletar as opiniões de empreendedores sobre o tema.

Para Turato (2013) a pesquisa qualitativa é utilizada quando o pesquisador deseja investigar os significados que um indivíduo ou grupo de indivíduos conferem a um fenômeno que lhes diz respeito. Assim, pesquisadores qualitativistas não pretendem generalizar seus resultados, mas possibilitar generalizações de novos conceitos e pressupostos levantados na conclusão de uma pesquisa.

A opção por adotar a abordagem qualitativa se baseia ainda em Godoy (1995) que menciona que na escolha da abordagem deve-se levar em conta a possibilidade de responder a questão de pesquisa. Além disso, quando se utilizam dados com o objetivo de ilustrar e discutir um fenômeno, não acontecendo análises estatísticas, a pesquisa se classifica como qualitativa.

Quanto aos objetivos a pesquisa pode ser categorizada como exploratória, pois se pretendeu abordar um tema que não era totalmente dominado pelo pesquisador, conduzindo ao aprofundamento de conhecimentos para que posteriormente pudesse orientar outras pesquisas, inclusive de abordagem quantitativa (GIL, 2002).

Preliminarmente, foi realizada pesquisa exploratória de caráter teórico para embasar os temas estudados, para que em seguida pudesse ser realizada uma pesquisa exploratória de caráter empírico.

A amostra adotada para essa pesquisa é a não probabilística intencional. A amostra não probabilística é comumente utilizada nas pesquisas de abordagem qualitativa por não possuir a intenção de generalizar os resultados, indo de encontro ao desejo de pesquisadores qualitativistas. (TURATO, 2013). Esse tipo de amostragem não apresenta fundamentação estatística ou matemática e depende unicamente dos critérios do pesquisador, levando em consideração os objetivos que pretende alcançar. (GIL, 2008). A amostra não probabilística intencional foi escolhida por permitir a escolha dos respondentes considerando a preocupação com a representatividade da amostra em relação à população total estudada. (TURATO, 2013). 
Para operacionalização da pesquisa de campo foi definido como instrumento de coleta de dados um questionário composto de questões abertas, cuja ordem e formulação das questões são uniformizadas e para as quais não se ofereçam alternativas de resposta, ou seja, o respondente foi convidado a emitir sua opinião. Esse tipo de questionário apresenta-se como um instrumento precioso para a coleta de dados quando a quantidade de possíveis respostas é ampla ou imprevisível, permitindo ao pesquisador assegurar-se da qualidade das respostas obtidas do interrogado. (LAVILLE; DIONNE, 1999). O referido questionário foi adaptado de Costa (2012).

A coleta de dados foi realizada em abril de 2015 tendo como respondentes um grupo de empreendedores participantes do curso de capacitação em Gestão Empresarial do Programa Bom Negócio Paraná - Núcleo da UNESPAR (Universidade Estadual do Paraná), no município de Paranaguá - Paraná.

\subsection{O MUNICÍPIO DE PARANAGUÁ}

O município de Paranaguá juntamente com mais seis municípios (Antonina, Guaraqueçaba, Guaratuba, Matinhos, Morretes e Pontal do Paraná) formam a Região Turística do Litoral do Paraná (SAMPAIO, 2006).

Paranaguá está situado no litoral do Paraná, distante 87 quilômetros da capital Curitiba e tem como limites ao norte o município de Guaraqueçaba, ao sul o município de Matinhos, a oeste Morretes e Antonina, e a leste Pontal do Paraná e o Oceano Atlântico, como pode ser visto na figura 1. (BONFIM, 2015). Os acessos a este município podem ser feitos pela rodovia federal BR 277 e pelas rodovias estaduais PR 407, PR 411 e PR 412, além de uma rodovia municipal. O meio de transporte predominante é o rodoviário, porém, o município conta com infraestrutura ferroviária, marítima e aérea (IPHAN, 2007). 
FIGURA 1 - LOCALIZAÇÃO DO MUNICÍPIO DE PARANAGUÁ NO BRASIL E NO ESTADO DO PARANÁ

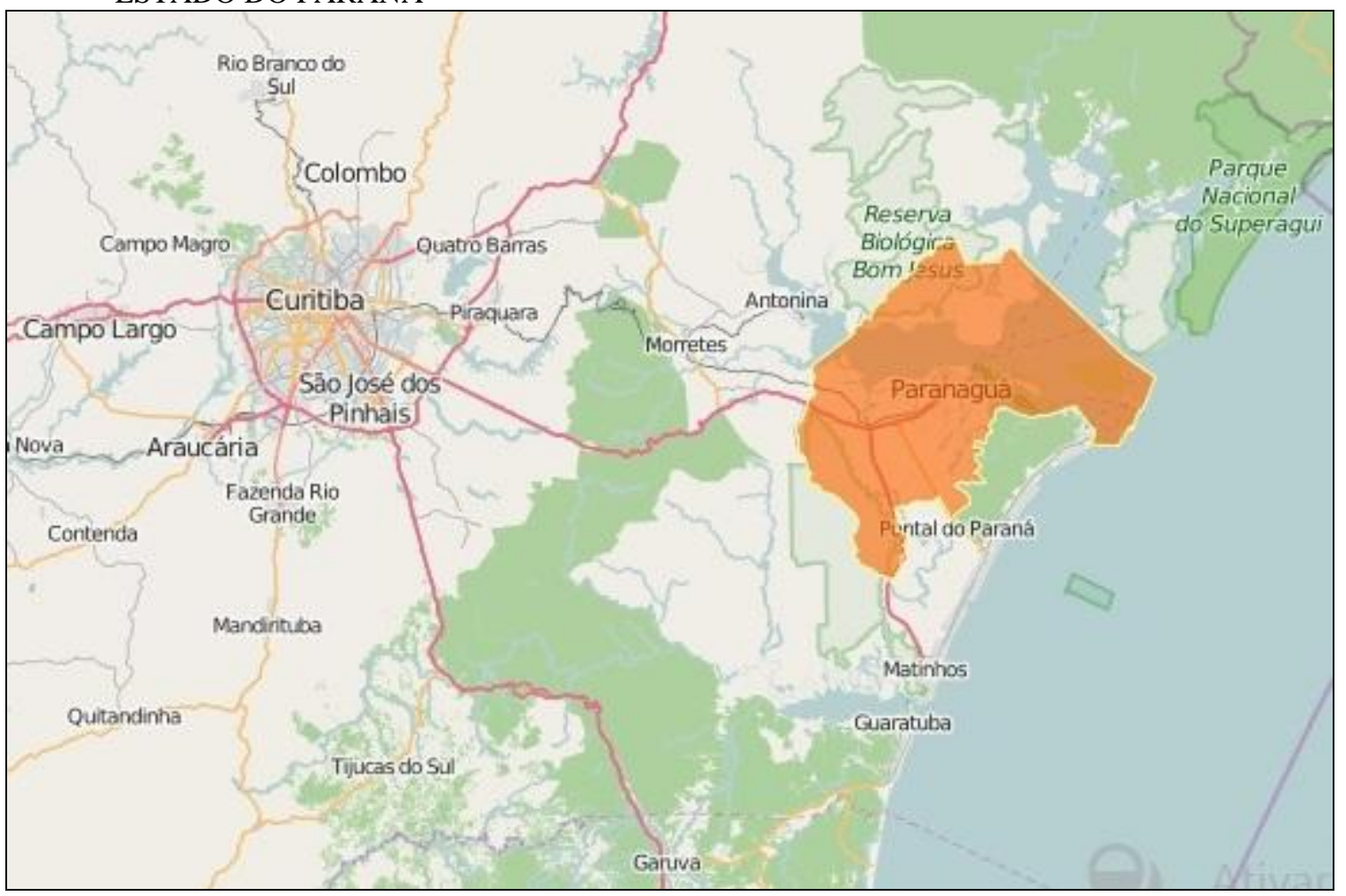

FONTE: IBGE (2015).

De acordo com o Instituto Brasileiro de Geografia e Estatística - IBGE (2015), Paranaguá possui população de 149.467 mil habitantes e área de $826,675 \mathrm{~km}^{2}$. Tendo sua economia voltada ao Porto de Paranaguá e em partes ao turismo no município, que conta com um dos principais destinos turísticos do Estado do Paraná: a Ilha do Mel.

Paranaguá e seu destino turístico Ilha do Mel, compõem a lista dos 65 destinos prioritários do Ministério do Turismo, representando o Estado do Paraná, juntamente com Curitiba e Foz do Iguaçu, conforme informações obtidas a partir do Instituto Paranaense de Desenvolvimento Econômico e Social (IPARDES, 2008).

O litoral do Paraná apresenta um mercado favorável ao desenvolvimento do turismo de negócios, pois possui um forte conjunto econômico derivado, na sua maior parte, das atividades portuárias dos municípios de Antonina e Paranaguá. Dessa forma, o Porto de Paranaguá se apresenta em um cenário favorável ao desenvolvimento do turismo de negócios e possibilita que o município de Paranaguá obtenha grande geração de renda nesse segmento do turismo. (ANACLETO; LEÃO; JORGE, 2013). 


\section{APRESENTAÇÃO DOS RESULTADOS}

Participaram da pesquisa um total de 12 (doze) empreendedores proprietários de micro e pequenas empresas com atividades direta ou indiretamente relacionadas ao turismo no município de Paranaguá, como lanchonetes, restaurantes, loja de roupas e utensílios, imobiliária, salão de beleza e fabricante de carrinho para vendedores ambulantes.

Os participantes apresentaram idades entre 26 e 59 anos, sendo 7 (sete) do sexo feminino e 5 (cinco) do sexo masculino, como pode ser observado na figura 2.

\section{FIGURA 2 - SEXO DOS ENTREVISTADOS}

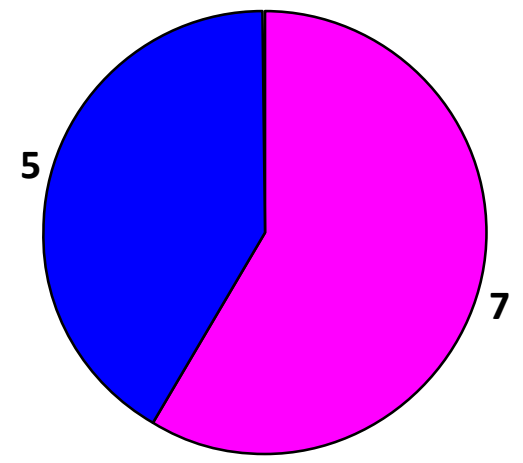

$\square$ Feminino

Masculino

FONTE: Pesquisa de Campo (2015).

Dentre os entrevistados, 8 (oito) afirmaram que possuíam alguém na família que estava sendo ou já havia sido empreendedor. Foram citados: filhos, tios, mãe, irmã, pai e sobrinho. Nessa questão, 4 (quatro) dos entrevistados afirmaram não possuir nenhum caso de empreendedor na família, como pode ser visualizado na figura 3. 
FIGURA 3 - EMPREENDEDORES QUE JÁ TEM OU JÁ TIVERAM EMPREENDEDOR NA FAMÍLIA

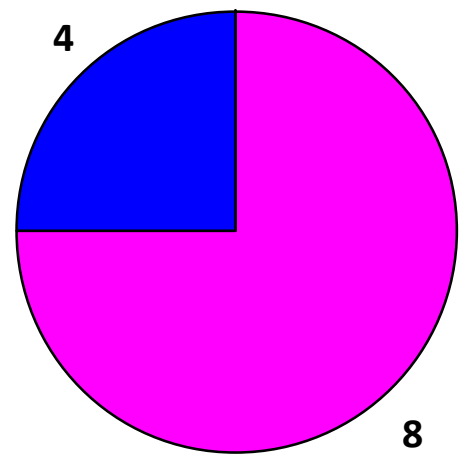

FONTE: Pesquisa de Campo (2015).

Pode-se aqui considerar o que afirma Dolabela $(1999,2008)$ que o empreendedor sofre influência do ambiente em que vive e que se o ato de abrir uma empresa for visto como algo positivo, maiores serão as chances de um indivíduo constituir um empreendimento próprio. Acrescenta-se que o fato de os empreendedores entrevistados terem casos de empreendedores na família, pode ter sido visto como incentivo a empreender. Dessa forma, a influência da família pode consistir em uma forte contribuição na idealização de um empreendimento (SILVA; FONSECA; ARAÚJO, 2015).

Com relação à escolaridade dos entrevistados, foi identificado que 1 (um) possuía ensino fundamental completo, 2 (dois) ensino médio incompleto, 5 (cinco) ensino médio completo, 1 (um) ensino técnico completo e 3 (três) ensino superior completo, como pode ser visto na figura 4. Isso demonstra que empreender independe da escolaridade. 


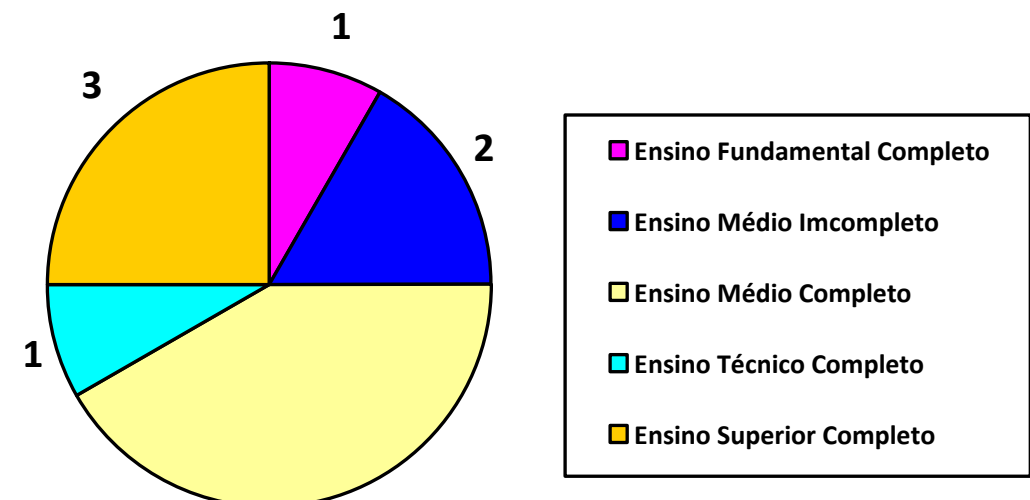

5

FONTE: Pesquisa de Campo (2015).

Ao questionar sobre as características pessoais que seriam mais importantes para o gerenciamento de uma empresa, foi solicitado aos empreendedores que as escolhessem em uma escala de 1 a 5 , sendo 1 - Discordo totalmente; 2 - Discordo parcialmente; 3 - Nem concordo nem discordo; 4 - Concordo parcialmente; e 5 Concordo totalmente para as seguintes características: liderança, autoconfiança, perseverança, necessidade de realização, iniciativa, valores pessoais, foco e criatividade. A média dos resultados obtidos pode ser observada na tabela 1.

$\begin{array}{llllll}\text { TABELA } & 1-\text { CARACTERÍSTICAS PESSOAIS IMPORTANTES PARA } & \mathrm{O}\end{array}$ GERENCIAMENTO DE UMA EMPRESA

\begin{tabular}{l|c}
\multicolumn{1}{c|}{ Característica } & Média Obtida \\
\hline Liderança & 4,75 \\
\hline Autoconfiança & 4,33 \\
\hline Perseverança & 4,42 \\
\hline Necessidade de Realização & 4,60 \\
\hline Iniciativa & 4,83 \\
\hline Valores Pessoais & 4,50 \\
\hline Foco & 4,83 \\
\hline Criatividade & 4,58 \\
\hline
\end{tabular}

FONTE: Pesquisa de Campo (2015).

Notou-se que as características citadas pelos entrevistados como mais importantes foram iniciativa e foco, com média 4,83 cada, seguidas de liderança, com média de 4,75. Cabe ressaltar que todas as características apresentaram médias altas, 
entre 4 (concordo parcialmente) e 5 (concordo totalmente). A partir dos resultados obtidos na pesquisa de campo, expostos na tabela 1, considerou-se poder inferir que todas as características pessoais foram apontadas pelos entrevistados como importantes para o gerenciamento de uma empresa.

Na questão seguinte se perguntava qual a importância da intuição para o sucesso do negócio. As alternativas eram: muita, pouca ou nenhuma importância e os participantes foram convidados a justificar suas respostas. Os resultados apontaram que 2 (dois) consideraram a intuição como pouco importante para o sucesso. Destes, 1 (um) justificou que não deveriam "começar nada usando sentimentos, mas sim o aprimoramento" e o outro não justificou. Por outro lado, 10 (dez) dos respondentes consideraram a intuição como muito importante para o sucesso empresarial. As justificativas foram: "A intuição é uma maneira de sentir e prever problemas ou soluções"; "Pela visão de estar atento às necessidades e a lei da oferta e da procura"; "Sentir diante dos fatos o caminho a ser seguido mesmo contrariando opiniões"; "Faz com que o empreendedor caminhe com firmeza e adquira confiança em si"; "Saber do que se é capaz e confiar na intuição; obter resultados positivos”. Um total de 4 (quatro) dos respondentes que consideraram a intuição como muito importante não justificaram suas respostas.

Quando questionados sobre como descreveriam a si mesmos enquanto líderes das suas empresas, as respostas obtidas foram: "Objetiva, determinada, sociável, compreensiva, criativa, perseverante e amiga"; "Um buscador de soluções"; "Uma pessoa que busca aprimorar seus conhecimentos para ter um diferencial, ser pontual ao atender as necessidades de seus clientes"; "Determinada, focada no que quero obter, persistente"; "Que tem dificuldades de delegar tarefas e fazer cobranças"; "Perseverante"; "Com gentileza e sempre sendo o exemplo, pois só se pode pedir quando se dispõem a trabalhar"; "Busco sempre agradar meus clientes"; "Disciplinada sou pontual, gosto de começar e terminar o que faço, trabalho em equipe e busco ter novas ideias"; "Ouvindo ideias diferentes das minhas, sendo acessível a outras pessoas para o trabalho em equipe". Um total de 2 (dois) dos participantes não responderam a essa questão.

Ao serem perguntados se os participantes se consideravam empreendedores, 4 (quatro) não responderam e os outros 8 (oito) responderam que se consideravam 
empreendedores. Ao solicitar uma justificativa para as respostas, obtiveram-se as seguintes: "Gosto de inovar em tudo que faço, sempre tentando melhorar"; "Considero atualmente estar preparado"; "Acredito no que faço"; "A partir do momento que você necessita de algo e o busca, consegue realizar e conquistar seus objetivos, você já é empreendedor"; "Por necessidade comecei uma nova profissão, aprendendo na prática, me especializei e hoje tenho meu escritório"; "Busco aprender sempre mais"; "Sonho em ser independente"; "Tenho minha empresa e busco mantê-la em atividade".

Referente à elaboração de um Plano de Negócios antes de colocar seus negócios em funcionamento, 2 (dois) não responderam, 2 (dois) afirmaram ter feito um Plano de Negócios, 4 (quatro) que não fizeram um Plano de Negócios e 4 (quatro) afirmaram ter feito outro tipo de planejamento, como pode ser visto na figura 5.

$\begin{array}{llllllll}\text { FIGURA } 5 & - & \text { ELABORAÇÃO } & \text { DE } & \text { UM } & \text { PLANO } & \text { DE NEGÓCIOS } & \text { PELOS } \\ \text { EMPREENDEDORES } & & & & \end{array}$
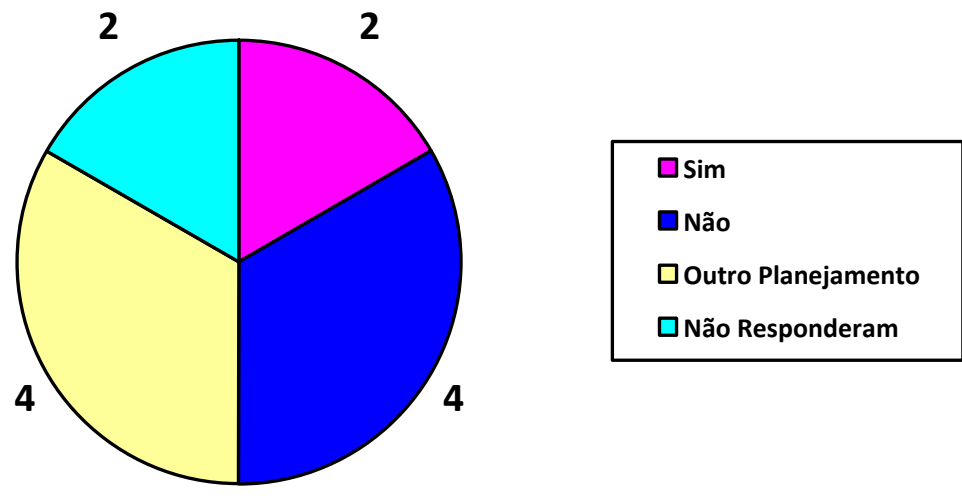

FONTE: Pesquisa de Campo (2015).

Os outros tipos de planejamento citados por 4 (quatro) dos respondentes foram: "Pesquisa sobre ramo de negócio que iria ocupar se já tinha na cidade, como iria executar e divulgar"; "Pesquisa sobre atendimento das necessidades dos clientes"; "Planejamento da data de abertura e planejamento de médio e longo prazo"; "Pesquisa e planejamento sobre diferenciais do mercado".

Quando abordados sobre a importância dada por eles às relações internas e externas na empresa e sobre quais contatos consideravam mais importantes, 1 (um) não 
respondeu, 9 (nove) responderam que todos os contatos eram importantes e os outros 2 (dois) citaram que os contatos internos eram mais importantes, pois era a partir deles que aconteciam os contatos externos.

Na questão seguinte se abordava se as políticas públicas existentes estimulavam a atividade empreendedora relacionada ao turismo em Paranaguá. Oferecia-se como alternativas de respostas sim e não e solicitava-se que o respondente justificasse sua escolha. 5 (cinco) responderam não e citaram as seguintes justificativas: "Demora na liberação do alvará e fiscalização"; "A cidade carece de infraestrutura para o turismo"; “Os pontos turísticos que estão sob cuidados do poder público estão esquecidos, totalmente precários"; "Não há incentivo"; "É precário". Dos 7 (sete) empreendedores que consideraram que as políticas públicas estimulavam o empreendedorismo no setor de turismo da cidade, apenas 4 (quatro) justificaram: “As pessoas estão sendo mais bem preparadas para empreender a partir da realização de cursos"; "Há incentivo, mas ainda é preciso se atentar mais para o patrimônio histórico"; "Em alguns aspectos sim, mas ainda há muito que se investir"; "Divulgação da cidade dentro e fora do país como lugar onde se oferecem oportunidades".

As perspectivas para o mercado turístico da cidade de Paranaguá foram respondidas por 10 (dez) dos participantes: "Um bom gerenciador, dando contínuo auxílio à limpeza e manutenção da cidade. Como oportunidade pode ser apontada a criação de pequenas empresas"; "A cidade tem um grande potencial, mas falta mais atenção por parte das autoridades"; "Que os governantes tenham uma visão melhor e saibam aproveitar as oportunidades do turismo na cidade"; "As perspectivas só melhorarão se houver uma mudança na secretaria de turismo"; "Se realmente forem realizadas as obras para o porto turístico, a tendência é trazer novas oportunidades"; “Ótima, mas a longo prazo com empresas ligadas à área de guias de turismo bilíngues com total atendimento aos serviços relacionados ao turismo"; "Crescimento geral, de forma plena e gradativa principalmente com os jovens, pois eles tem novos sonhos e disposição para o trabalho"; "Nenhuma perspectiva"; "Há muitas chances de crescimento do mercado turístico, mas depende muito dos nossos governantes"; "Promissora, podem ser exploradas oportunidades de negócios com oferecimento de capacitações e treinamentos". Os outros 2 (dois) participantes não responderam a esse questionamento. 


\section{CONSIDERAÇÕES FINAIS}

A partir da pesquisa realizada considera-se que a importância da ligação entre turismo e empreendedorismo ficou evidenciada, levando-se em conta que o turismo depende de inovações e atualizações constantes, criando ou modernizando seus produtos e serviços.

Também se pode reforçar que o empreendedorismo se dá a partir da iniciativa de empreendedores. Isso denota a importância do empreendedor enquanto ator de desenvolvimento social. Por sua vez, a tendência a empreender aumenta quando pessoas estão inseridas em um ambiente propício ao empreendedorismo, ambiente este em que empreender seja visto como algo positivo.

Para identificar se um ambiente turístico é favorável ao empreendedorismo, devem ser observados os seguintes atores: a comunidade local/regional através do seu envolvimento no turismo, lideranças regionais e cooperação de forma a entender as dinâmicas de relações que podem vir a favorecer a criação de empreendimentos; os empreendedores locais, a partir de suas características pessoais e o desenvolvimento do negócio; as parcerias: sejam de fornecedores e/ou prestadores de serviços e o Estado, ou seja, as autoridades que o representam. Também deve ser levada em consideração a legislação vigente para a localidade onde será inserido o empreendimento e para o ramo de atividade do empreendimento a ser iniciado. No entanto, o excesso de burocracia e exigências fiscais podem ser fatores determinantes para o início de um empreendimento. Da mesma forma, devem ser levados em consideração o acesso ao crédito, se é facilitado ou dificultado, e o funcionamento correto do sistema bancário.

Vislumbrando tais aspectos, nesse estudo se buscou identificar o que seria um ambiente propício ao empreendedorismo no turismo. Para isso foi realizada uma pesquisa de campo com empreendedores participantes do curso de capacitação básica em Gestão Empresarial do Programa Bom Negócio Paraná na cidade de Paranaguá em abril de 2015 .

Os resultados apontaram que 8 (oito) dos empreendedores entrevistados possuíam casos de empreendedores na família, o que indicou que estes poderiam ter iniciado suas empresas por incentivo de pessoas do seu círculo familiar que consideravam a ação empreendedora como positiva independente da escolaridade 
apresentada. Para 9 (nove) dos entrevistados, as redes de contato internas e externas às empresas foram mencionadas como importantes.

Com relação as perspectivas dos entrevistados para com o turismo no município, observou-se que foi dada ênfase ao poder público como principal ator para realização de mudanças positivas para o turismo no município. Foi citada ainda a necessidade de iniciativas empreendedoras pelo setor privado no que se refere ao atendimento ao turista.

Pode-se concluir, a partir da pesquisa de campo, que um ambiente propício para empreender no setor de turismo em Paranaguá é aquele em que existe apoio e incentivo por parte de familiares e amigos e onde exista o comprometimento do poder público a fim de incentivar a ação empreendedora criando micro e pequenos empreendimentos que venham atender da melhor forma os turistas do município.

Para Pimentel et al. (2013), parte da política pública federal nos últimos anos tem envolvido a simplificação de trâmites legais e burocráticos para formalização de micro e pequenos empreendimentos, no entanto, no setor de turismo ainda faltam muitos esclarecimentos, aperfeiçoamentos e difusão de informações que permitam seu uso de maneira mais efetiva. Nesse sentido, as políticas nacionais devem ser desenvolvidas de maneira democrática e participativa, onde as lideranças locais ocupem um papel relevante na promoção do desenvolvimento social, econômico e cultural, fomentando o empreendedorismo em suas localidades.

Para Borges Jr et a.l (2013), é de fundamental importância que o Estado, quando da promoção de políticas públicas de fomento ao empreendedorismo, consiga integrar ações de várias áreas do poder público, como saneamento, energia, telefonia, transporte, educação e saúde, além da promoção da cultura e atividades educacionais voltadas ao empreendedorismo, realizada através de programas e projetos.

Constatou-se serem poucos os estudos e pesquisas que analisam as políticas públicas que influenciam empreendedores e seus empreendimentos, sendo menor o número de estudos com foco nas políticas públicas de apoio ao empreendedorismo (BORGES JR et al., 2013). Menor ainda é o número de pesquisas específicas sobre as políticas públicas para o empreendedorismo no setor de turismo, consistindo assim em um campo vasto para investigação científica. 
Sugerem-se como temas para pesquisas futuras, o aprofundamento de estudos teóricos relacionados ao ambiente considerado como propício ao empreendedorismo no setor de turismo bem como a realização de estudos empíricos que comprovem a teoria e que possam trazer elementos que venham a somar com as teorias existentes.

\section{REFERÊNCIAS}

ANACLETO, A.; LEÃO, A. S.; JORGE, L. F. O turismo de negócios no Litoral do Paraná. Revista Eletrônica de Administração e Turismo - ReAT, v. 3, n. 2, Jul./Dez., 2013.

BONFIM, M. Localização do Município de Paranaguá. Disponível em: <http://www.milenabonfim.blogspot.com.br/2011/07/parabéns-paranagua.html?m=1>. Acesso em: 14/04/2015.

BYGRAVE, W.; MINNITI, M. The Social Dynamics of Entrepreneurship. Entrepreneurship theory and practice. Texas: Baylor University, 2000.

BORGES JR, C.; FERREIRA, V. R. S; NAJBERG, E; COSTA, C. S. Políticas públicas de apoio ao empreendedorismo: Análise de sua presença (ou ausência) em duas regiões turísticas do estado de Goiás. VI ENCONTRO DE ESTUDOS EM ESTRATÉGIA. Bento Gonçalves/ RS. 19 a 21 de maio de 2013.

COSTA, L. B. Ambiente Turístico Empreendedor: Estudo da hotelaria de Gramado e Canela. XXII COMPEHT Brasil - CONGRESSO PAN-AMERICANO DE ESCOLAS DE HOTELARIA, GASTRONOMIA E TURISMO. 14-18 de Outubro de 2012.

CRESWELL, J. W. Projeto de Pesquisa: métodos qualitativos, quantitativos e misto. 3. ed. Porto Alegre: Artmed, 2010.

DOLABELA, F. Oficina do Empreendedor. São Paulo: Editora Cultura, 1999.

. Pedagogia Empreendedora. São Paulo: Editora Cultura, 2003.

O Segredo de Luísa. 3. ed. São Paulo: Editora Cultura, 2008.

DORNELAS, J. C. A. Empreendedorismo: transformando ideias em negócios. Rio de Janeiro: Campus, 2001.

GIL, A. C. Como elaborar projetos de pesquisa. 4. ed. São Paulo: Atlas, 2002. 
Métodos e técnicas de pesquisa social. 6. ed. São Paulo, Atlas, 2008.

GLOBAL ENTREPRENEURSHIP MONITOR - GEM. Empreendedorismo no Brasil. Curitiba, IBQP, 2010.

GLOBAL ENTREPRENEURSHIP MONITOR - GEM. Empreendedorismo no Brasil. Curitiba, IBQP, 2013.

GODOY, A. S. Pesquisa qualitativa: tipos fundamentais. RAE, São Paulo. v. 35 n. 3, p. 20-29, maio/junho 1995.

IBGE. INSTITUTO BRASILEIRO DE GEOGRAFIA E ESTATÍSTICA - CIDADES. Paranaguá. Disponível em:

$<$ http://www.cidades.ibge.gov.br/xtras/temas.php?lang=\&codmun=411820\&idtema=16 \&search=IIs\%EDntese-das-informa\%E7\%F5es $>$. Acesso em: 14/04/2015.

IPARDES - INSTITUTO PARANAENSE DE DESENVOLVIMENTO ECONÔMICO E SOCIAL. Cadeia Produtiva do Turismo no Paraná: Estudo sobre as Regiões Turísticas do Estado. Curitiba: IPARDES, 2008.

IPHAN - INSTITUTO DO PATRIMÔNIO HISTÓRICO E ARTÍSTICO NACIONAL. Instrução do Processo de Tombamento do Setor Histórico de Paranaguá - Paraná. Elaborado por Humberto Fogassa Arquitetura. Curitiba: 2007. (arquivo digital).

LAVILle, C; DIOnNE, J. A Construção do Saber: Manual de Metodologia da pesquisa em ciências humanas. Porto Alegre: Artmed; Belo Horizonte: Editora UFMG, 1999.

PIMENTEL, A; VIOLENTO, A; RODRIGUES, C. G. O; JULIÃO, D. P; JUER, E; LOHMANN, J. B. Empreendedorismo e formalização de atividades de turismo em ambientes naturais. Observatório de Inovação em Turismo - Revista Acadêmica, v. VII, n. 4, Rio de Janeiro, março 2013.

SAMPAIO, R. Ocupação das orlas das praias paranaenses pelo uso balneário. Curitiba, 2006. Tese. (Curso de Doutorado em Meio Ambiente e Desenvolvimento, da Universidade Federal do Paraná).

SANTOS VIEIRA, R; SANTOS, A; ROJO, C. A. Perfil Empreendedor dos participantes das turmas do Programa Bom Negócio Paraná - Núcleo de Cascavel. In: II COBRAGEN - CONGRESSO BRASILEIRO DE GESTÃO DE NEGÓCIOS, 07 a 11 de Outubro de 2013, Cascavel. 
SILVA, W. A. C; FONSECA, R. A.; ARAÚJO, E. A. T. Comportamento empreendedor e trajetória empresarial de fundadores de MPEs em Barão de Cocais/ MG. Revista de Empreendedorismo e Gestão de Pequenas Empresas - REGEPE. v. 4, n. 2, 2015.

TOMAZZONI, E. L. Turismo e Desenvolvimento regional: Modelo APL TUR aplicado à Região das Hortênsias (Rio Grande do Sul - Brasil). 2007. Tese (Doutorado em Ciência da Comunicação) - ECA, Universidade de São Paulo.

TURATO, E. R. Tratado da Metodologia da Pesquisa Clínico-Qualitativa: Construção teórico-epistemológica, discussão comparada e aplicação nas áreas da saúde e humanas. 6. ed. Petrópolis, RJ: Vozes, 2013. 